\title{
Hedges as a Task-Based Training for Composition-Industrial Students
}

\author{
Sameer Al-Salihi ${ }^{1}$ \\ ${ }^{1}$ Senior Lecturer, English Language Center, Jubail Industrial College, Saudi Arabia \\ Correspondence: Sameer Al-Salihi, English Language Center, Jubail Industrial College, Saudi Arabia. E-mail: \\ salihi_s@jic.edu.sa
}

Received: April 12, 2015 Accepted: May 5, 2015 Online Published: August 31, 2015

doi:10.5539/ells.v5n3p156 URL: http://dx.doi.org/10.5539/ells.v5n3p156

\begin{abstract}
This research article would turn over an attempt made to investigate why certain composition students could not interact with employing some hedging structures (usually defined as claim-mitigating markers). This inability would negatively affect developing confidence required to enhancing written and oral communication when using English with others. Two main reasons behind the students' inability to use most of the types of hedging structures have been found out to be their failure to recognize the hedge functional constrains due to the issue that hedges are not incorporated as an essential subject in their composition textbooks and the focus of teaching them has been on their syntactic and semantic functions - not on their pragmatic one. This situation has cogently been supported by means of further research and analyzing the students' performance reflected on their academic quizzes.

This article would also subsume a suggestive methodology given to a sample of Jubail-Industrial-College students to cope with hedging structures where they received condensed training dealing with defining hedges, usage motivation, and a concise taxonomy under the power of a blend of socio-pragmatic strategies. The training would be found to reflect a positive feedback confirmed by the analysis of their post-training performance which has revealed some improvement. Practical recommendations would follow the findings, which could be up for discussion.
\end{abstract}

Keywords: hedges, communication, task-based training

\section{The Need for the Study}

The inability of a controlled group of learners (see 5.1. below) to hedge well would definitely impede employing some pragmatic (unstated meaning) devices, e.g., hedges, which would be an obstacle to produce or comprehend a text with hedges.

This problem could be empirically solved in terms of answering these two questions:

a) Can these students produce a writing unit incorporating a reasonable usage of hedges?

b) Are they aware of the pragmatic function of hedges?

Answering these questions involves the writer to give a training course and follow the post-training result from which he could reach the answers (see section 5 below).

\section{Overview of Hedges}

Hedge, according to some dictionaries, is to "avoid committing yourself to the truth value of what you say" (Scott, Foremen Intermediate Dictionary), or "avoid giving a direct answer to a question" (Longman Dictionary of Contemporary English). Both explanations show avoidance from full commitment, relieving a speaker from some of the responsibility laid by the statement or claim, e.g.,

(1) What caused the fire could be the machine operator.

Where the speaker employs the modal "could" in sentence(1) to intentionally afford a note to the listener about the accuracy of the statement showing that what is claimed has been tentative; he/she, accordingly, gets himself/herself off the hook; otherwise, sentence(1), without "could", might be a case of accusation; so "could" is a means of protection. This would match Yule's (1996) idea about hedges as they are described as a "number of expressions we use to indicate that what we're saying may not be totally accurate." This description might be reflected in the interpretation of these two examples: (hedges are in bold type) 


\section{(2) A- As far as I know, they're married.}

B- He couldn't live without her, I guess. (Ibid, p. 38)

In the discourse analysis and speech act theory, a hedge is connected to logical properties of words or phrases as being able "to make things fuzzier or less fuzzy" (Lakoff, 1972, p. 195). The term "fuzzy" has powerful effect that makes the speaker avoid responsibilities or commitments to the truth of his/her saying; to exemplify, consider the effect of protection that the speaker has when he says:

(3) A - Who are those people?

B - I'm not sure. I think they are the murderers.

Here "I'm not sure" and "I think" have not already committed the speaker to accounting for a probable reaction towards the proposition, e.g., the clause: "they are the murderers", which might put him/her in a situation to face an accusation. "Well" is considered a hedge in Southerland and Katamba (2005, p. 584) as it reflects a mitigation function in such a structure as:

(4) A - Could you type this letter for me before you leave?

B - Well, I was really planning an early start on my weekend so I thought I'd leave a few minutes early.

Palmer's (1997) claim on "epistemic modality" as underlying Hedging meaning on the grounds that it expresses the degree of commitment to the truth value of what is being said though he does not use the term "Hedge". He claims that a sentence like:

(5) He may/must/will be in his office.

may be roughly paraphrased: It is possible that...., or The only possible conclusion is that... (Ibid, p. 153). Inspired by Lyon's (1977, p. 797) definition of "epistemic modality", Vold (2006, p. 64) selects a group of modality markers that express "uncertainty", such as possibly, probably, perhaps, etc., to be regarded as having hedging function. them Some expressions (adverbials) like "kind of, sort of, about, somehow, rather, a little bit, not very much, etc.", which provide vagueness or impreciseness have been included within hedges in House and Kasper, (1981, p. 183). They show that speakers use the above hedging terms to avoid precise specification or to modulate the impact an utterance is likely to have. In Quirk et al. (1972, p. 218) these adverbials are referred to as "downtoners/ compromisers" and exemplified as (6) here:

(6) A - I kind of like him.

B - I quite enjoyed the party. (Ibid, p. 218)

Portner (2006, p. 154) views hedges to "involve reference to facts that we know". He simplifies the way of realizing it by providing this implicit paraphrase: "Given what I Know". To exemplify the notions above, consider these two examples:

(7) Speaker A: I wouldn't like to invite Sam to the party.

Speaker B: You may be right. (Epistemic)

(8) Speaker A: I failed the English Exam again.

Speaker B: In view of the rules of improvement in this school, you may need an remedial English course soon. (Deontic)

The auxiliary modal "may" in the speaker's (7-B) utterance, expresses "possibility (right or wrong) leading to uncertainty", and therefore, it is for sure a way of hedging. Using the paraphrase above yields:

- Given what I Know, you may be right.

This paraphrase steps up the degree of possibility by detaching the speaker from what is right or wrong since the statement with "may" has occurred by virtue of my knowledge, not others'. The "may" expression in (8-B) is not about "what the speakers knows", but about the intention or willingness through advisability which is in view of the "rules of improvement of the school", i.e., deontic modality is about "rules, circumstances, obligations, permissions, willingness, wishes, etc.", and thus, it has nothing to do with the function of hedges. In is also noticed that hedges are deemed one type of "interpersonal metadiscourse markers" in Dafouz (2008, p. 98); they refer to "markers that withhold full commitment to the statement displayed in the text." In this work, three categories of hedges are singled out: epistemic verbs (may, might, would), probability adverbs (perhaps, maybe) and epistemic expressions (e.g., it is likely..., it is probable...). Cherry $(1988$, p. 79$)$ refers to the mitigating function of hedges where they weaken the strength of the illocutionary force of propositions. Hypothetical (conditional) constructions have been included as hedges in Heng and Tan (2002). 
In his classification hedges, Martin-Martin (2008, pp. 136-139) approaches them to have a list of forms and functions sorted out under three functional strategies:

indetermination, subjectivisation, and depersonalization. They have developed from both linguistic and situational contexts. The list comprises such lexico-grammatical and syntactic forms as modal verbs, cognition verbs, epistemic constructions, opinion phrases and clauses, conditional and impersonal constructions. The hedging classification in this article would adopt several structures and terminology of this model of classification.

\section{Hedging Classification}

Hedges can be classified into these logical relationships:

3.1 Indetermination: by making a statement lacking clarity and precision, a case which does not lead up to a definite result or ending (The American Heritage College Dictionary, 3rd edition). It can include these types:

A) Model constructions, with epistemic meaning in which the speaker/writer "explicitly qualifies his commitment to the truth of the proposition expressed by the sentence he utters" (Lyons, 1977, p. 797). They may include:

i) auxiliary verbs: e.g., may/might, can/could, would

ii) modal nouns: e.g., possibility, assumption

iii) modal adjectives: e.g., likely, possible, probable

iv) model adverbs: e.g., perhaps, probably, possibly

B) Epistemic non-action constructions (mostly precede by "it" and followed by the prepositional phrase "to me/us" which make something appear to be true while it is likely to be so:

i) verbs: e.g., It seems, appears to me/us that...

ii) adverbs: seemingly, apparently e.g., There is seemingly nothing to do.

C) Downtoners which have a lowering effect, reducing the force of the element they modify (see Quirk et al., 1972, p. 218f). They may include:

i) approximating adverbs: almost, approximately, nearly, generally

ii) compromising adverbs: sort of, kind of, rather, quite

iii) compromising phrases: in some respect, to some extent, more or less

D) Quantifiers: which describe the limits of something or someone without being precise about the nature of those limits: some, a little, a bit of, a lot of, e.g., I know some people who don't respect the poor.

E) Frequency adverbs: usually, sometimes, and occasionally

F) Conditional (hypothetical) constructions: which leaves the question of fulfillment unresolved and leads in turn to uncertainty and impreciseness exemplified by: If/Unless- clauses, e.g., If you eat candy, you will get fatter/ Unless the boss agrees, they can't postpone the appointment.

3.2 Subjectivisation: which signals that what is being said is the speaker's/writer's own (subjective) opinion or self-involvement. This strategy helps the writer to "show respect for the reader's alternative opinion and invite the reader to become involved in the communicative situation." (Martin-Martin, Ibid, p. 6). It appears to include:

A) Cognition verbs (always preceded by first personal pronouns and followed by that-clause), e.g., I think / I believe / I guess / I suppose that...

B) Stance-showing expressions, e.g., in my opinion, in our view, to the best of my knowledge, in my experience, as far as I know

3.3 Objectivisation: whose constructions make the proposition out of personal prejudice by allowing the deletion of the agent or allowing the agent to be replaced by non-human entity, and hence, allowing the avoidance of commitment or direct personal attribution. It probably includes:

A) Agentless-passive constructions, e.g., It has been said that..., It has been suggested that ...

B) Impersonal active constructions: which generally shift responsibility to methods e.g., The findings/suggestions/analyses reveal that ...

C) Impersonal clause: which comprises the impersonal subject pronoun? 
"it" plus the indeterminate verbs "seem/ appear" plus that clause, e.g., It seems/appears that...

D) Impersonal pronoun "one", e.g., One should save one's questions until the end.

The performance of their quizzes and daily task proved to lacking the use of a number of hedges, creating a need for a special training.

\section{Hedge-Employing Motivation}

It could be able to see that this employment is generally motivated by "fuzziness, uncertainty, or indetermination" extended over a proposition (a discourse). This motivation may stem from two interrelated pragmatic factors:

a) Evasiveness: with the sense of evading responsibility of what has been said, e.g.,

(1) The accident you had will be horrible pictures in your mind if you continue dreaming about it.

"if-clause" in (1) helps the speaker/writer indicate a lack of commitment to the truth value of that strong claim by virtue of the condition directly connected to it. According to Slager-Meyers (1994), evasiveness is not a way of showing confusion or

b) Politeness: where the speaker/writer can use a hedging form as "threat-minimizing" action that softens a "potential face-threatening activity" when his/her statement has information which might be considered socially, morally, or legally sensitive to listener/reader. Simply, mitigation and/or indirectness are the socio-linguistic strategies which are more likely to be triggered off as a self-protection motive for politeness. Consider this example:

(2) I suggest that your C.V. must be reviewed by the committee before the interview.

The initial phrase in (2) deliberately weakens the strength of the embedded claim by the indetermination expressed by the verb suggest ( to provide a subjective idea which could be exposed to different judgments) as opposed to a verb like "decide" which has the power of determination. And it is normally polite, in personal interactions, to engender a claim that is less serious, unpleasant or sensitive to the hearer/reader.

\section{Task-Based Training: Description}

The participants were given 5-day condensed training held at week 6 after Quiz 2 - a time which had ensured the situation of the students' a lack of using hedges. Thirty minutes in the first two days were allotted to equip them with an overview of the definition of hedging structures, motivation of employing them as well as a concise classification under the power of a blend of syntactic-pragmatic strategies. Students were provided with handouts matching the overview. In the three other days, in addition, task-based activities (discussed below) were assigned to help develop and build their skill in employing hedges. This tutorial will be effectively reflected on their major productive part, Mid-Term Exam, which was to be evaluated and analyzed. Later on, there should be a time for integrating it in the ELT training.

\subsection{The Participants}

The participants under investigation were seven adult students having a Composition Course (taught by the writer of this paper)after successfully completing a prep-year English Course of two semesters in which they are equipped with a general English course, including basic English grammar; they entered the English Language Center in Jubail Industrial College(Saudi Arabia) about one and a half years ago; they were all repeaters, sitting in one class constituting the experimental group for the researcher. These students were highly motivated because they didn't want to experience "repeated failure". The participants' Composition performance of their quizzes and daily task proved to lacking the use of a number of hedges. Even if they use it, they cannot recognize its function well. This situation contributed to creating a need for a special training.

\subsection{Training Methodology}

These participants were to be involved in hedge-recognizing and building activities in which all students, including lower level ones, will employ these theoretical and practical ways in the process of effective writing and speaking. The controlled-class discussion would be a blend of discussions and tutorial based on a real world and meaningful language use to upgrade their skills and knowledge on the area concerned. Accordingly, these steps were followed:

Step 1) Setting the Atmosphere: defining the objective, procedures, need and creativity.

Step 2) Preparing the ground: Non-use of Hedges 
The participants were randomly divided into two groups under the supervision of their tutor; Group A (four students) had to offer (say and write out) audience of their peers "situations" (often examples from their real writing) with functions of strong claims lacking hedges (factual and nonfactual) represented by As and "objections" represented by Bs, both exemplified in:

\section{i) Speaking:}

A false accusation or a note of accusation, e.g.,

1) A: Yesterday, you wasted your time watching that movie.

B: How Come?! How do you know?

A claim, e.g.,

2) A: JIC students study full-time.

B: Who said that? Are they all?

A face-threatening statement, e.g.,

3) A: Hassan, the teacher will mark you down tomorrow!

B: Why? I'll ask the teacher about that.

A promise, e.g.,

4) A: You will find us here tomorrow; there's going to be trouble.

B: Are you sure?

A request expecting a refusal e.g.,

5) A: I was going to talk about your quiz mistakes in the classroom.

B: This isn't OK, is it?

A: Sorry.

ii) Writing: (from their daily assignments and quizzes)

Descriptions: (As in the following propositions are the instructor's choices written on the board; Bs are suggestive comments given by both the instructor and participants; the propositions are not hedged.)

6) A: Jubail is big and has beautiful weather in winter.

B: I object; Jubail sometimes does not have beautiful weather in winter because it is humid and cold.

7) (Describing a colored picture)

A: The Malayan flag has four colors. They make that flag nice and bright.

B: How do you know that it is nice and beautiful? It's just normal.

8) (a picture- telling story)

A: The boy fell down because he was struck by lightning.

(This is not clear from the picture.)

B: Who told you this? The fact is that he was daydreaming and suddenly slipped.

A: The boys were happy as they sat together and ate fish.

B: They weren't. They were just chatting, fighting or complaining.

9) (Strong claims)

A: In wars, people die or are seriously injured.

B: Your statement appears to be vague.

10) (Future-embarrassing request)

A: I'll talk about your picnic in the coffee shop.

B: This isn't all right. It's something personal!

Step 3) Setting the Effect: The speakers (Group A) normally made it awkward to issue flat (here non-hedging) language functions, and the audience(Group B)seemed to have access to the exact meaning and is highly likely to oppose and come out with abrupt reactive answers which may cause disputes; here the instructor can intervene 
to show the expected effect on both speakers and listeners where the former did not hedge his claim and be liable to face a negative reaction, often a rude attack from the latter. Such examples help the student apply what he/she is learning to real-life problems. Each participant is required to contribute at least one idea.

Step 4) Self-Defense Procedure: Using the hedges

The same structural ideas in the examples in Step(2) above are to be repeated next day, each with one of the hedging devices, to show the main pragmatic function: mainly an elastic commitment, mitigating phrases or polite requests: see above (section 5.2)

Step 5 Feedback: Showing the importance

The instructor here solicits students' opinions of the two sets of answers, which often shows how to marry a hedge expression and a claim, e.g.

- Why does the second answer look more supportive or?

- What is the purpose/function of "maybe" in this or that context?

- Do you have to use "In my opinion..." instead of "I believe..."? Why?

It is worth mentioning here that the instructor has emphasized the use of one-word or phrasal hedges as they could simplify the process of the hedge's choice; using clausal or wordy expression might make training more complex.

Step 6 Suggested Practices for Homework Assignments: Output

At the end of training, the third day, the participants are given Homework Assignments which are composed of exercises matching the examples taught in during training as well as the following exercises:

\subsection{Homework Assignments}

i) Fill-in-the-Blank Practice

Students are given short paragraphs having gaps for a hedging structure. These paragraphs help them to provide hedges of different types, e.g., one day I could travel where no one before has done it. It like a dream when I buy a flying car and take my best friend with me to Paris, for example, and

Eiffel Tower. I consider this the greatest dream I've ever had. visit the

\section{ii) Claim-Weakening}

The students are requested to weaken (mitigate or moderate) strong claims by employing hedging structures, e.g.,

a) Arabs will have their own missiles to travel to the space in the near future.

Answer: they can use "may/might/ could instead of will", "Its possible/probable/likely that...", "There is a certain/slight/good/ possibility that...",

b) The colors of that flag represent power, unity, and freedom.

Answer: I think/guess/believe that...

In my opinion/ To my Knowledge/ As far as I know...

It appears/seems that...

c) (From a picture) The shops of this city close early.

Answer: Some shops of this city...

In some/most parts of this city shops close early.

iii)) Non-Linear Textual Statements:

The participants are supplied with work sheets on which a graph, map, or table (taken from their textbook) is drawn. On the basis of the drawings given, the participants are requested to deliver possible stance, comments or reasons on the claims drawn out of these graphic tasks (see Heng and Tan, 2005, p. 205). This exercise might draw upon the use of hedges, e.g.,

Expected output: It appears from the map of Canada that.../ This map indicates.../ The findings suggests... 


\subsection{Result}

The post-training resulted in a highly positive performance reflected in their college test results and speaking assignments. It really shows a noticeable increase in using hedges. It stresses a cogent preference for quantifiers. The comparative picture (brought in by the performance of pre-and post-training) remarkably indicates that the types of hedging devices created by the participants were, to some extent, varied, especially with quantifiers and modals. This may happen due to:

a) awareness created by training

b) feeling of the Hedge-pragmatic power, producing a high interest in employing them.

\section{Recommendations}

Both instructors and students should cooperate together in creating socio-cultural situations where they can show the need for hedges as toning down structures through which people can communicate softly and smoothly; nevertheless, these three points might be recommended for those within the learning process:

a- Instructors ought to indicate that Hedging Devices are highly helpful (or even necessary ) whenever someone, in a contextual situation, wants or plans to mitigate his/her claim for respect purpose or protect himself/herself from a possible attack of an opponent.

b- Students write down the final output-statements underlining the hedging devices and simply indicating their functions.

c- alongside with Stage(b), the student should know that hedges do not only have a pragmatic effect on the reader but also enhance the discourse coherence in terms of their transitional function. Consequently, our writing is definitely optimized by hedge employment. Transitional devices work like bridges, linking together various objects, ideas, paragraphs, or even whole parts of a paper.

\section{Conclusion}

This study has presented hedges as a specific area of pragmatics where the focus has been on their social function in communications - not on their syntactic use (as modifiers, for example). Their communicative significance lies in their need to modulate some speech acts, mitigate strong claims to reach certain level of acceptability among speakers or writers and/or protect themselves against opposition. The study has introduced short-term training to intermediate-leveled Arab students of composition during an academic course of study. The training was a basic prerequisite for a satisfactory mastery of the most common hedging structures (especially one-word). It has mostly taught them how to be confidently uncertain about their claims, opinions, and comments, i.e., how to cooperate with a listener when they may or may not share him/her opinion. After training the students concerned showed a prominent increase in the use of hedges to the extent that they have felt comfortable when they claim out or express their points of view.

In view of the results arrived at, some suggested exercises and recommendation have been introduced at the end of the study.

\section{References}

Brown, P., \& Levinson, S. (1987). Politeness: Some universals in language usage. Cambridge: Cambridge University Press.

Chafe, W. (1994). Discourse, Consciousness, and Time. Chicago University Press.

Cherry, R. (1988). Politeness in Written Persuasion. Journal of Pragmatics, 12, 63-81. http://dx.doi.org/10.1016/0378-2166(88)90020-3

Coates, J. (1983). The Semantics of the Modal Auxiliaries. London: Croom helm.

Dafouz-Milne, E. (2008). The Pragmatic Role of Textual and Interpersonal Metadiscourse Markers in the Construction of Persuasion. Journal of Pragmatics, 40, 95-113. http://dx.doi.org/10.1016/j.pragma.2007.10.003

Halliday, M. (1970). Functional Diversity in Language as Seen from a Consideration of Modality and Mood in English. Foundations of Language, 6, 322-361.

Heng, S. W., \& Tan, H. (n.d.). Maybe, perhaps, I believe, You could - Making Claims and the Use of Hedges. Retrieved from http://www.melta.org.my/ET/2002/wp09.htm/ 
House, J., \& Kasper, G. (1981). Politeness markers in English and German. In F. Coulmas (Ed.), Conversational routine: Explorations in standardized communication situations and prepatterned speech. The Hague: Mouton. http://dx.doi.org/10.1515/9783110809145.157

Hyland, K. (1998). Hedging in scientific research articles. Amsterdam/Philadelphia: John Benjamins Publishing Company. http://dx.doi.org/10.1075/pbns.54

Lakoff, G. (1972). Hedges: A study in meaning criteria and the logic of fuzzy concepts. Chicago Linguistics Society Papers, 8, 183-228.

Longman Dictionary of Contemporary English. (1995). Longman Group Ltd.

Lyons, J. (1977). Semantics (vol. 2). Cambridge University Press.

Markannen, R., \& H. Schroder. (1997). Hedging: A Challenge for Pragmatics and Discourse Analysis. In R. Markannen \& H. Schroder (Eds.), Discourse Approaches to the Analysis of a Pragmatic Phenomenon in Academic Texts (pp. 21-41). Berlin: Walter de Gruyter.

Martin, P. (2008). The Mitigation of Scientific Claims in Research Papers: A Comparative Study. Longman.

Meechan, M., \& Rees-Miller, J. (2005). Language in Social Contexts. In W. O'Gardy et al. (Eds.), Contemporary Linguistics (5th ed.). Bedford/St. Martin's.

Myers, G. (1989). The pragmatics of politeness in scientific articles. Applied Linguistics, 10(1), 1-35. http://dx.doi.org/10.1093/applin/10.1.1

Palmer, F. R. (1986). Mood and Modality. Cambridge: Cambridge University Press.

Palmer, F. R. (1997). Semantics (2nd ed.). Oxford University Press.

Portner, P. (2006). Meaning. In Fasold \& Corne-Linton (Eds.), An Introduction to Language and Linguistics. Cambrige University Press.

Quirk, R., Greenbaum, S., \& Leech, G. (1972). A Concise Grammar of English. Cambridge: Cambridge University Press.

Salager-Myer, F. (1997). I think that perhaps you should: A study of hedges in written scientific discourse. In T. Miller (Ed.), Functional Approaches to Written Text: Classroom Applications. Washington, D.C: United States Information Agency.

Southerland, R., \& Katamba, F. (2005). Language in Social Contexts. In W. O'Gardy et al. (Eds.), Contemporary Linguistics (5th ed.). Bedford/St. Martin's.

Swales, J., \& Feak, C. (1994). Academic writing for graduate students (pp. 86-90). Ann Arbor, MI: The University of Michigan.

The American Heritage College Dictionary. (1999). 3rd Edition. Houghton: Mifflin Company.

Vold, E., T. (2006). Epistemic Modality Markers in Research Articles. International Journal of Applied Linguistics, 16(1). http://dx.doi.org/10.1111/j.1473-4192.2006.00106.x

Webster's II New Riverside Dictionary. (1984). New York: Berkley.

Wishnoff, J. R. (2000). Hedging Your Bets: L2 Learners' Acquisition of Pragmatic Devices in Academic Writing and Computer-Mediated Discourse. Second Language Studies, 19(1), 119-148.

Yule, G. (1996). Pragmatics. Oxford University Press.

\section{Copyrights}

Copyright for this article is retained by the author(s), with first publication rights granted to the journal.

This is an open-access article distributed under the terms and conditions of the Creative Commons Attribution license (http://creativecommons.org/licenses/by/3.0/). 